\title{
Combination therapy versus celecoxib, a single selective COX-2 agent, to reduce gastrointestinal toxicity in arthritic patients: patient and cost-effectiveness considerations
}

\author{
This article was published in the following Dove Press journal: \\ Open Access Rheumatology: Research and Reviews \\ 3 August 2011 \\ Number of times this article has been viewed
}

\author{
Marina Scolnik' \\ Gurkirpal Singh ${ }^{2}$ \\ 'Sección Reumatología, Servicio \\ de Clínica Médica, Hospital Italiano \\ de Buenos Aires, Buenos Aires, \\ Argentina; ${ }^{2}$ Division of \\ Gastroenterology and \\ Hepatology, Stanford University \\ School of Medicine, Stanford, \\ Palo Alto, CA, USA
}

\begin{abstract}
Nonsteroidal anti-inflammatory drugs (NSAIDs) are widely used for treating symptoms of rheumatologic diseases, such as osteoarthritis and rheumatoid arthritis. Knowing their side effects and the way to minimize them is a medical responsibility. To reduce NSAIDrelated risk, clinicians should choose a gastroprotective strategy. This may include coprescribing a traditional NSAID with a proton pump inhibitor or a high-dose histamine 2-receptor antagonist ( $\mathrm{H}_{2} \mathrm{RA}$ ), or using a cyclo-oxygenase (COX)-2 selective inhibitor or a COX-2 with a proton pump inhibitor. Assessing each patient's risk (cardiovascular and gastrointestinal) is a priority in order to decide the best intervention to minimize toxicity. In this article, we review some of the common interventions for reducing the gastrointestinal side effects of NSAIDs.
\end{abstract}

Keywords: arthritis, osteoarthritis, celecoxib, nonsteroidal anti-inflammatory drugs, gastrointestinal toxicity, cost-effectiveness

\section{Introduction}

Osteoarthritis is the most common form of arthritis worldwide. It is strongly associated with aging. Radiographic osteoarthritis is found in $80 \%$ of people by the age of 80 years, but only half of them have symptoms. ${ }^{1}$ Joint degeneration leads to difficulty in ambulation and mobility, having a great functional impact. Osteoarthritis is associated with considerable medical costs, mainly because of joint replacements. Acetaminophen (paracetamol) is recommended as a first-line symptomatic treatment by various scientific societies (European League Against Rheumatism [EULAR], American College of Rheumatology [ACR]). Nonsteroidal anti-inflammatory drugs (NSAIDs) are used widely in the management of osteoarthritis. The meta-analysis of Towheed et al found that NSAIDs were more efficacious than acetaminophen for osteoarthritis pain, yet the risk of discontinuing therapy because of gastrointestinal adverse events was $50 \%$ higher with NSAIDs than with paracetamol. ${ }^{2}$ This important side effect is even more frequent in this elderly osteoarthritis population.

Rheumatoid arthritis is a systemic autoimmune disease affecting $0.5 \%-1.0 \%$ of the population worldwide, showing a female-to-male excess of 2-4-fold. ${ }^{3}$ It is characterized by synovial joint inflammation that can lead to bone erosions and joint destruction. Many new treatments have been developed in recent decades. Diseasemodifying antirheumatic drugs are the gold standard treatment for disease control. NSAIDs continue to be helpful in conjunction with disease-modifying antirheumatic
Correspondence: Gurkirpal Singh Division of Gastroenterology and Hepatology, Stanford University School of Medicine, 175 Eleanor Drive, Woodside, CA 94062, USA

Tel + I 6508040502

$\mathrm{Fax}+\mathrm{I} 6503670200$

Email gsingh@stanford.edu 
drugs, because they reduce pain and inflammation with rapid onset. However, they are not disease-modifying drugs and can cause important gastrointestinal and cardiovascular side effects. Cyclo-oxygenase (COX)-2 inhibitors are as effective as traditional NSAIDs and can be used with the same treatment objectives. They are associated with fewer gastrointestinal side effects but have a similar cardiovascular side effect profile. ${ }^{4}$

\section{Mechanism of action: COX-I and COX-2 inhibition}

The best characterized mechanism of action of NSAIDs is inhibition of the COX activity of prostaglandin $\mathrm{G} / \mathrm{H}$ synthase 1 and 2, also referred to as COX-1 and COX-2. These enzymes catalyze the transformation of arachidonic acid to a range of lipid mediators, termed prostaglandins and thromboxanes. Therapeutic doses of aspirin and other NSAIDs reduce prostaglandin biosynthesis in humans, and there is a reasonably good correlation between the potency of these drugs as COX inhibitors and their anti-inflammatory activity. COX-1 is expressed constitutively in all cells, and is found in particularly high concentrations in platelets, vascular endothelial cells, the stomach, and kidney collecting tubules. COX-1 function is essential for maintenance of normal endocrine and renal function, gastric mucosal integrity, and hemostasis. COX-2 activity is almost undetectable in most tissues under physiological conditions, but its activity is rapidly increased in response to inflammatory or mitogenic stimuli. However, COX-2 also is constitutively expressed in certain areas of the kidney and brain ${ }^{5}$ and is induced in endothelial cells by laminar shear forces. ${ }^{6}$ Therefore, distinguishing COX-1 as a constitutive enzyme and COX-2 as a purely inducible enzyme that accounts for the formation of prostanoid in disease is an oversimplification of biologic reality. Importantly, COX-1, but not COX-2, is expressed as the dominant, constitutive isoform in gastric epithelial cells and is the major source of cytoprotective prostaglandin formation. Inhibition of COX-1 at this site is thought to account largely for the gastric adverse events that complicate therapy with traditional NSAIDs, thus providing the rationale for the development of NSAIDs specific for inhibition of COX-2.7,8

The COX isoenzyme selectivity of a particular drug is critically dependent on its concentration. There is a substantial variability between patients in plasma concentration after oral administration of a standard therapeutic dose and also in the extent of inhibition of each COX-isoform. Most traditional NSAIDs inhibit both COX-1 and COX-2 with little selectivity, although some, conventionally thought of as traditional NSAIDs, eg, diclofenac, exhibit a higher selectivity for COX-2. ${ }^{8}$

\section{Efficacy of celecoxib versus traditional NSAIDs}

Celecoxib is used in the treatment of osteoarthritis and rheumatoid arthritis at doses of 200-400 mg daily. Many trials have demonstrated that celecoxib has similar efficacy compared with NSAIDs in the management of pain and inflammation, both in rheumatoid arthritis and osteoarthritis.

\section{Celecoxib versus naproxen}

Celecoxib was compared with naproxen in one randomized clinical trial. ${ }^{9,10}$ This was a 12 -week multicenter study comparing celecoxib at doses of $100 \mathrm{mg}, 200 \mathrm{mg}$, or $400 \mathrm{mg}$ ( $\mathrm{n}=240, \mathrm{n}=235$, and $\mathrm{n}=218$, respectively) twice daily versus naproxen $500 \mathrm{mg}$ twice daily $(\mathrm{n}=225)$ and placebo $(n=231)$ in adults with rheumatoid arthritis of at least 3 months' duration, with functional class I-III. Withdrawals due to lack of efficacy were 65/225 (29\%) in the naproxen group, $67 / 240$ (28\%) in the $100 \mathrm{mg}$ celecoxib group, 50/235 (21\%) in the $200 \mathrm{mg}$ group, and 59/217 (27\%) in the $400 \mathrm{mg}$ group. ACR20 responses were $81 / 225$ in the naproxen group, $95 / 240$ in the celecoxib $100 \mathrm{mg}$ group, 103/235 in the $200 \mathrm{mg}$ group, and 85/217 in the $400 \mathrm{mg}$ group. The relative risk (RR) of improvement was 1.1 (95\% confidence interval [CI] 0.8-1.4),1.2 (95\% CI 1.0-1.5), and 1.1 (95\% CI 0.9-1.4), respectively, indicating no statistically significant difference. The only statistically significant difference between the treatments in any of the outcomes measured was that individuals taking $200 \mathrm{mg}$ celecoxib twice daily showed greater improvement than those taking naproxen measured by patient and physician global assessment and those taking $400 \mathrm{mg}$ twice daily on the Health Assessment Questionnaire functional disability score. ${ }^{11}$ Another trial by Bensen et al ${ }^{12}$ compared the efficacy of celecoxib at doses of $50 \mathrm{mg}, 100 \mathrm{mg}$, or $200 \mathrm{mg}$ twice daily with that of naproxen $500 \mathrm{mg}$ twice daily or placebo for 12 weeks in patients with osteoarthritis of the knee. All celecoxib doses were efficacious compared with placebo. The higher doses of celecoxib (100 mg and $200 \mathrm{mg}$ twice daily) were similarly efficacious, and the magnitude of improvement observed with these dosing regimens was comparable with that seen for naproxen. Kivitz et a $\mathbf{~}^{13}$ studied 1061 patients with symptomatic osteoarthritis of the hip randomized to receive celecoxib $100 \mathrm{mg}, 200 \mathrm{mg}$, or $400 \mathrm{mg} /$ day, naproxen $1000 \mathrm{mg} /$ day, or placebo, for 12 weeks. Celecoxib $200 \mathrm{mg} /$ day and $400 \mathrm{mg} /$ day were similarly efficacious and comparable with naproxen. Goldstein et a ${ }^{14}$ found similar 
improvements in patient and physician global assessments of efficacy in 537 patients with osteoarthritis or rheumatoid arthritis randomized to treatment with celecoxib $200 \mathrm{mg}$ twice daily $(\mathrm{n}=270)$ or naproxen $500 \mathrm{mg}$ twice daily $(n=267)$ for 12 weeks

\section{Celecoxib versus diclofenac}

Emery et $\mathrm{al}^{15}$ studied the efficacy of celecoxib in patients with rheumatoid arthritis. In total, 326 patients received celecoxib $200 \mathrm{mg}$ twice daily and 329 received diclofenac $75 \mathrm{mg}$ twice daily for 24 weeks. There was no documented difference between the two drugs by physician assessment, patient assessment, number of swollen or tender joints, visual analog pain score, early morning stiffness, or C-reactive protein. However, the mean number of swollen and tender joints did decrease over the course of the study. ACR20 response at 24 weeks was $25 \%$ in the celecoxib group and $22 \%$ in the diclofenac group. McKenna et $\mathrm{al}^{16}$ compared the efficacy of celecoxib $100 \mathrm{mg}$ twice daily with that of diclofenac $50 \mathrm{mg}$ three times daily and placebo in 600 patients with osteoarthritis of the knee in a 6-week, randomized, controlled trial. Primary efficacy measures (index joint pain by visual analog scale and Western Ontario and McMaster Universities [WOMAC] index) indicated no statistically significant differences between celecoxib and diclofenac.

\section{Celecoxib versus naproxen versus diclofenac}

The SUCCESS-I study ${ }^{17}$ included a total of 13,274 patients with osteoarthritis of the knee, hip, or hand, from 39 countries, of whom 8800 were randomly assigned to celecoxib $100 \mathrm{mg}$ or $200 \mathrm{mg}$ twice daily for 12 weeks, and 3489 and 905, respectively, were assigned to a nonselective NSAID, ie, diclofenac $50 \mathrm{mg}$ or naproxen $500 \mathrm{mg}$ twice daily for 12 weeks. The drugs were similarly effective in treating osteoarthritis (measured by visual analog pain score, patient global assessment, and WOMAC index).

\section{Gastrointestinal toxicity with NSAIDs}

A major disadvantage of NSAID use is the gastrointestinal side effects. These range from abdominal pain, nausea, diarrhea, and dyspepsia to more serious events, such as gastric or duodenal ulcers, anemia, and bleeding, or perforated ulcer. These side effects are due to the simultaneous inhibition of COX-1 and COX-2. Clinical symptoms are poor predictors of gastrointestinal injury. NSAID-induced ulcers are frequently asymptomatic.
As many as $25 \%$ of chronic NSAID users will develop ulcer disease, ${ }^{18,19}$ and $2 \%-4 \%$ will bleed or perforate, ${ }^{20,21}$ especially those who have been designated as being in a high-risk category. ${ }^{22,23}$ In a large meta-analysis, the overall risk for these complications in patients taking NSAIDs was approximately $2.4 .{ }^{24}$ However, the risk is markedly increased in patients who fall into various high-risk categories. ${ }^{24-27}$

According to the 2009 guidelines from the American College of Gastroenterology, patients are classified as being at high, moderate, or low risk for NSAID gastrointestinal toxicity. ${ }^{28}$ High-risk patients are those with a history of complicated peptic ulcer disease or multiple (at least two) risk factors; moderate-risk patents are those with one to two risk factors, ie, age $>65$ years, high-dose NSAID therapy, previous history of an uncomplicated ulcer, concurrent use of aspirin (including low-dose), corticosteroids, or anticoagulants; and low-risk patients are those with no risk factors.

The distinct roles of the two COX enzymes in patients with peptic ulcers are unknown. COX-2, as well as COX-1, have been detected in apparently normal gastrointestinal epithelium, so both of them may help to protect the gastric mucosa. ${ }^{29}$ It appears that an inhibition of both enzymes is necessary for gastric damage.

\section{Role of Helicobacter pylori}

A comprehensive meta-analysis of 16 case-controlled studies demonstrated that the risk of peptic ulcer bleeding was increased by a factor of 1.79 with Helicobacter pylori infection, by 4.85 with NSAID usage, and by 6.13 in the presence of both NSAID use and $H$. pylori infection, strongly suggesting an additive effect. ${ }^{30,31}$ An updated meta-analysis showed similar findings. ${ }^{31}$ There is a potential advantage of testing for $H$. pylori infection and eradicating the infection if positive in patients requiring long-term NSAID therapy.

\section{Prevention strategies}

Two methods are commonly employed to prevent the development of peptic ulceration and mucosal injury in patients taking NSAIDs: ${ }^{32}$ (1) prophylaxis with a proton pump inhibitor or a prostaglandin analog (such as misoprostol) or high-dose histamine 2-receptor antagonist $\left(\mathrm{H}_{2} \mathrm{RA}\right)$; (2) with substitution of a traditional NSAID by a COX-2 inhibitor.

\section{High-dose $\mathrm{H}_{2} \mathrm{RAs}$}

Double doses of $\mathrm{H}_{2} \mathrm{RAs}$ are effective for reducing the risk of endoscopic NSAID-induced gastric and duodenal ulcers. Standard doses of $\mathrm{H}_{2} \mathrm{RAs}$ are only effective at reducing the risk of NSAID-induced duodenal ulcers, but not gastric 
ones. ${ }^{32,33}$ Several trials have demonstrated superior healing rates in NSAID-induced ulcers with proton pump inhibitors compared with ranitidine. ${ }^{34-36}$

More recently, Goldstein et $\mathrm{al}^{37,38}$ published the results of two multicenter, randomized, double-blind trials that compared the healing rates of gastric ulcers induced by use of NSAIDs. Esomeprazole $20 \mathrm{mg}$ and $40 \mathrm{mg}$ daily were compared with ranitidine $300 \mathrm{mg}$ daily, given for 8 weeks, in patients with at least one documented gastric ulcer who required continuous NSAID treatment. In the first study $(n=399)$, healing rates for both esomeprazole groups were superior to ranitidine $(P=0.01) .{ }^{38}$ However, in the more recently published study $(n=410)$, no statistically significant difference was found between the groups, despite having the same design and equivalent sample sizes as the previous study, although the numeric results were similar. ${ }^{37,39}$

In a literature review of seven clinical trials performed by Yeomans et al, ${ }^{40}$ after 8 weeks of treatment with ranitidine, gastric ulcer healing rates were 50\%-74\%. However, 8-week gastric healing rates were $92 \%$ and $88 \%$ with esomeprazole $40 \mathrm{mg}$ and $20 \mathrm{mg}$, respectively, $87 \%$ and $84 \%$ with omeprazole $40 \mathrm{mg}$ and $20 \mathrm{mg}$, and $73 \%$ and $66 \%$ with lansoprazole $30 \mathrm{mg}$ and $15 \mathrm{mg}$. Duodenal ulcer healing rates were $92 \%$ for omeprazole $20 \mathrm{mg}$ versus $81 \%$ for ranitidine. NSAIDassociated gastric ulcers are more likely to heal when patients receive proton pump inhibitor cotherapy rather than ranitidine. $^{39}$

In 2011, the US Food and Drug Administration approved a fixed-dose combination of ibuprofen $800 \mathrm{mg}$ and famotidine $26.6 \mathrm{mg}$. This approval was supported by data from two randomized controlled trials, REDUCE-1 and REDUCE-2, ${ }^{41}$ which showed that of 1382 patients taking this combination, 930 had a significantly reduced risk of gastrointestinal ulcers at 24 weeks compared with 452 patients taking ibuprofen alone (14.1\% versus $26.5 \%$, respectively). This reduction was also seen in the subgroup of patients also receiving low-dose aspirin (14\% versus $34.5 \%$, respectively).

\section{Misoprostol}

Misoprostol was the first agent approved for the prevention of NSAID-related ulceration. In a large trial, 8843 patients with rheumatoid arthritis receiving continuous therapy with any of 10 NSAIDs were randomly assigned to receive $200 \mu \mathrm{g}$ of misoprostol or placebo four times daily for 6 months. ${ }^{42}$ Serious upper gastrointestinal complications were reduced by $40 \%$ (odds ratio [OR] $0.598 ; P=0.049$ ) among patients receiving misoprostol (25 of 4404 patients) compared with those receiving placebo (42 of 4439 patients). During the first month, more patients receiving misoprostol (20\%) than those on placebo $(15 \%)$ withdrew from the study, primarily because of diarrhea and related problems $(P<0.001)$.

A meta-analysis ${ }^{33}$ including 11 studies in 3641 subjects compared the incidence of endoscopic ulcers after at least 3 months of treatment with misoprostol versus placebo. The cumulative incidences of endoscopic gastric and duodenal ulcers with placebo were $15 \%$ and $6 \%$, respectively. Misoprostol significantly reduced the risk of gastric ulcer and duodenal ulcer by $74 \%$ (relative risk [RR] $0.26,95 \% \mathrm{CI}$ $0.17-0.39$ ), and 58\% (RR 0.42, 95\% CI 0.22-0.81). These relative risks corresponded to $12.0 \%$ and $3 \%$ absolute risk reductions for gastric and duodenal ulcers, respectively. The observed heterogeneity in these estimates was due to inclusion of all misoprostol doses in the analyses. Analysis of the misoprostol studies stratified by dose eliminated this heterogeneity.

Doses of misoprostol lower than $200 \mu \mathrm{g}$ four times daily have been used with some success and with fewer side effects. In one endoscopic trial, ${ }^{43} 1197$ patients taking long-term NSAIDs were randomly assigned to one of four regimens, ie, placebo four times daily, misoprostol $200 \mu \mathrm{g}$ twice daily, $200 \mu \mathrm{g}$ three times daily, or $200 \mu \mathrm{g}$ four times daily. The incidence of gastric ulcers was significantly lower in those receiving misoprostol twice daily $(8.1 \%$, difference $7.6 \%, 95 \%$ CI $2.7 \%-12.5 \% ; P=0.002)$, three times daily (3.9\%, difference $11.8 \%, 95 \%$ CI 7.4\%-16.3\%; $P<0.001$ ), and four times daily (4\%, difference $11.7 \%, 95 \%$ CI $6.7 \%-16.8 \% ; P<0.001)$ compared with placebo. The $7.5 \%$ incidence of duodenal ulcers detected by endoscopy with placebo was reduced to $2.6 \%, 3.3 \%$, and $1.4 \%$ with the three respective doses of misoprostol. There were fewer withdrawals due to adverse events in the groups receiving misoprostol twice daily and three times daily ( $12 \%$ for both) than in the group receiving it four times daily (20\%). Lower doses of misoprostol have not received Food and Drug Administration approval.

A meta-analysis of randomized controlled trials evaluating prevention strategies of NSAID-induced gastric ulceration showed that misoprostol was significantly more effective than $\mathrm{H}_{2} \mathrm{RAs}^{44}$

One randomized controlled trial ${ }^{45}$ compared misoprostol and lansoprazole in 537 patients without $H$. pylori who were long-term users of NSAIDs and had a history of endoscopically documented gastric ulcer. Patients were randomized to receive placebo, $200 \mu \mathrm{g}$ of misoprostol four times a day, or $15 \mathrm{mg}$ or $30 \mathrm{mg}$ of lansoprazole once daily. After 12 weeks, the incidence of endoscopically detected gastroduodenal 
ulceration was $49 \%$ with placebo, was significantly reduced with misoprostol (7\%) and, to a lesser extent, with both doses of lansoprazole ( $20 \%$ and $18 \%$, respectively). However, early withdrawals were more common in the misoprostol group. If withdrawals were included with endoscopic ulcers as failures of treatment, misoprostol and lansoprazole were similarly successful.

\section{Proton pump inhibitors}

Proton pump inhibitors are useful for the prevention of NSAID-induced ulcers. ${ }^{33,46}$ Proton pump inhibitors significantly reduced the risk of both endoscopic duodenal (RR $0.20,95 \%$ CI 0.10-0.39) and gastric ulcers (RR 0.39, 95\% CI $0.31-0.50)$ compared with placebo. The results were similar for both primary and secondary prophylaxis trials. ${ }^{33}$ Clinical studies of proton pump inhibitors have suggested that they are better tolerated but have slightly lower efficacy compared with full-dose misoprostol (200 $\mu \mathrm{g}$ four times daily) ${ }^{33}$

\section{COX-2 specific inhibitors: celecoxib}

Simon et al reported results of a randomized, controlled trial ${ }^{9}$ where an upper gastrointestinal tract endoscopic evaluation was made within 7 days prior to the first dose of study medication (placebo, celecoxib $200 \mathrm{mg} /$ day, $400 \mathrm{mg} /$ day, or $800 \mathrm{mg} /$ day, or naproxen $1000 \mathrm{mg} /$ day) and repeated at the final treatment visit (or early termination). Gastroduodenal ulcers developed in $4 / 99$ patients receiving placebo $(4 \%$, 95\% CI $0.1 \%-7.9 \%$ ), 9/148 receiving $100 \mathrm{mg}$ celecoxib $(6 \%, 95 \%$ CI $2.2 \%-10.0 \%) ; 6 / 145$ receiving $200 \mathrm{mg}$ celecoxib (4\%, 95\% CI $0.9 \%-7.3 \%$ ); and in $8 / 130$ receiving $400 \mathrm{mg}$ celecoxib twice daily $(6 \%, 95 \%$ CI $2.1 \%-10.4 \%)$. In comparison, of 137 patients receiving naproxen, 36 developed gastroduodenal ulcers $(26 \%, 95 \%$ CI 18.9\%-33.7\%). There were no statistically significant differences in the incidence of gastroduodenal ulcers between the placebo group and any of the celecoxib groups and no evidence of a dose response, whereas the incidence of ulceration in the naproxen group was significantly greater than in each of the other treatment groups $(P<0.001)$.

In another randomized controlled trial, ${ }^{15} 430$ patients on celecoxib $(n=212)$ or diclofenac $(n=218)$ underwent endoscopy. Fifteen percent of patients in the diclofenac group and 4\% in the celecoxib group developed gastroduodenal ulcers $(P<0.001)$, and the withdrawal rate because of gastrointestinal side effects was three times higher in the diclofenac group $(16 \%$ versus $6 \%, P<0.001)$.

The Celecoxib Long-Term Arthritis Safety Study (CLASS) trial ${ }^{20}$ included patients with osteoarthritis and rheumatoid arthritis. They were randomized to receive celecoxib $400 \mathrm{mg}$ twice daily $(\mathrm{n}=3987)$, diclofenac $75 \mathrm{mg}$ twice daily $(\mathrm{n}=1996)$, or ibuprofen $800 \mathrm{mg}$ three times daily $(n=1985)$. Seventy-two percent of the patients had osteoarthritis. Only the data from 6 months of follow-up have been published. Patients in the CLASS trial were permitted to take aspirin in doses of up to $325 \mathrm{mg}$ per day. Clinically relevant upper gastrointestinal ulcer complications (bleeding, perforation, obstruction) and symptomatic ulcers during the first 6 months of treatment were described as the two main outcome measures, comparing incidence rates for celecoxib and a traditional NSAID. It was concluded that, compared with traditional NSAIDs, celecoxib "was associated with a lower incidence of symptomatic ulcers and ulcer complications combined." An article in the Washington Post in August $2001^{47}$ and two letters published in JAMA in November $2001^{48,49}$ drew attention to the fact that the information available to the Food and Drug Administration contradicted these conclusions. Analysis according to a prespecified protocol showed similar numbers of ulcer-related complications in the comparison groups. Almost all the ulcer complications that had occurred during the second half of the trial were in users of celecoxib. ${ }^{50}$ Possible reasons for the apparent failure of celecoxib to reduce the risk of ulcer complications in this study include the use of low-dose aspirin in approximately $20 \%$ of patients and the use of a relatively high dose of celecoxib (800 mg per day). The reasons for the higher withdrawal rates in the CLASS trial are unclear.

Goldstein et al $^{14}$ determined gastroduodenal damage from endoscopy after 4,8 , and 12 weeks of treatment with celecoxib $200 \mathrm{mg}$ twice daily or naproxen $500 \mathrm{mg}$ twice daily in 537 patients with osteoarthritis or rheumatoid arthritis. The cumulative incidence of gastric and duodenal ulceration for celecoxib was $9 \%$ and for naproxen was $41 \%$. In the group that received celecoxib, the occurrence of ulcers was significantly associated with a number of factors, including H. pylori positivity, concurrent aspirin usage, and a history of ulcers.

In the SUCCESS-I study mentioned earlier, ${ }^{17} 8800$ patients with osteoarthritis were randomly assigned to celecoxib $100 \mathrm{mg}$ or $200 \mathrm{mg}$ twice daily for 12 weeks and 4394 were assigned to a nonselective NSAID (diclofenac $50 \mathrm{mg}$ or naproxen $500 \mathrm{mg}$ twice daily) for 12 weeks. The number of clinically significant ulcers was the same in the two groups (18 ulcers in each group, OR 2 for the NSAID group, 95\% CI 1.04-3.86). Only nine ulcer complications occurred in this study, seven in the combined NSAID group, and two in the combined celecoxib group $(P=0.008$; OR 7 for NSAID 
group, 95\% CI 1.46-33.8). There were fewer complications only in patients not taking concomitant aspirin (six in the NSAID group and one in the celecoxib group) and not in patients taking aspirin (one ulcer complication in each group).

Any potential gastroduodenal-sparing effect with selective COX-2 inhibitors may be abrogated or reduced when these agents are used concurrently with low-dose aspirin therapy for primary or secondary prevention of cardiovascular disease, but this remains controversial.

The results of a Cochrane meta-analysis ${ }^{33}$ demonstrate that misoprostol, proton pump inhibitors, and double doses of $\mathrm{H}_{2} \mathrm{RAs}$ are effective at reducing the risk of endoscopic gastric and duodenal NSAID-induced ulcers. Standard doses of $\mathrm{H}_{2} \mathrm{RAs}$ are not effective at reducing the risk of NSAIDinduced gastric ulcers. Misoprostol is the only prophylactic agent to date that has been evaluated in a true clinical outcome trial, and has been shown to reduce the risk of NSAID-related ulcer complications. However, its use is associated with significant adverse effects, particularly at higher doses.

\section{Combination therapy}

Data are conflicting as to whether COX-2 inhibitors provide additional protection against upper gastrointestinal complications compared with conventional NSAIDs combined with either a proton pump inhibitor or misoprostol.

Chan et $\mathrm{al}^{51}$ studied 287 patients who used NSAIDs for arthritis and presented with ulcer bleeding. After their ulcers had healed and they had tested negative for H. pylori, they were randomly assigned to receive either celecoxib $200 \mathrm{mg}$ twice daily plus daily placebo or diclofenac $75 \mathrm{mg}$ twice daily plus $20 \mathrm{mg}$ of omeprazole daily for 6 months. The endpoint was recurrent ulcer bleeding, which occurred in seven of 144 patients receiving celecoxib (4.86\%) and in nine of 143 patients receiving diclofenac plus omeprazole $(6.29 \%)$. They concluded that among patients with a recent history of ulcer bleeding, treatment with celecoxib was as effective as treatment with diclofenac plus omeprazole for prevention of recurrent bleeding.

Lai et $\mathrm{al}^{52}$ compared celecoxib $200 \mathrm{mg}$ daily $(\mathrm{n}=120)$ or naproxen $750 \mathrm{mg}$ daily and lansoprazole $30 \mathrm{mg}$ daily $(n=122)$ for 24 weeks in 224 patients who developed ulcer complications after NSAID use. The primary endpoint was recurrent ulcer complications, and 3.7\% (95\% CI 0.0\%-7.3\%) patients in the celecoxib group, compared with $6.3 \%(95 \% \mathrm{CI}$ $1.6 \%-11.1 \%$ ) in the lansoprazole group, developed recurrent ulcer complications (absolute difference -2.6\%, 95\% CI $-9.1 \%-3.7 \%$ ). Celecoxib was statistically noninferior to lansoprazole cotherapy in the prevention of recurrent ulcer complications.

In the CONDOR (Celecoxib versus Omeprazole aNd Diclofenac in patients with Osteoarthritis and Rheumatoid arthritis) study, ${ }^{53} 4484$ patients with osteoarthritis or rheumatoid arthritis at increased gastrointestinal risk were assigned to receive celecoxib $200 \mathrm{mg}$ twice daily $(\mathrm{n}=2238)$ or diclofenac slow-release $75 \mathrm{mg}$ twice daily plus omeprazole $20 \mathrm{mg} /$ day $(\mathrm{n}=2246)$ for 6 months. Patients included were older than 60 years, had a history of previous gastroduodenal ulcer, or had had a gastrointestinal hemorrhage more than 90 days before screening. They were negative for $H$. pylori. The primary endpoint was a composite of clinically significant events throughout the gastrointestinal tract (gastroduodenal, small bowel, or large bowel hemorrhage; gastric outlet obstruction; gastroduodenal, small bowel, or large bowel perforation; clinically significant anemia of defined gastrointestinal or presumed occult gastrointestinal origin, including possible blood loss from the small bowel; and acute gastrointestinal hemorrhage of unknown origin). The committee identified 20 primary endpoints in patients receiving celecoxib and 81 in patients taking diclofenac plus omeprazole. Using a Cox proportional hazards model, the proportion of patients reaching the primary endpoint during the 6-month study period was $0.9 \%(95 \%$ CI $0.5 \%-1.3 \%)$ in the celecoxib group and $3.8 \%$ (95\% CI 2.9\%-4.3\%) in the diclofenac plus omeprazole group (difference $2.9 \%, 95 \%$ CI $2.0 \%-3.8 \%$, $P<0.0001)$. The hazards ratio was 4.3 (2.6-7.0) in favor of celecoxib. The main driving force behind the primary endpoint was a hemoglobin decrease of $20 \mathrm{~g} / \mathrm{L}$ or more. In support of the primary analysis, treatment with celecoxib was associated with a lower rate of moderate-to severe abdominal symptoms and withdrawal because of gastrointestinal adverse events than was treatment with diclofenac plus omeprazole. This study focused not only on upper gastrointestinal events, but also on gastrointestinal outcomes in the lower gastrointestinal tract, that may be relevant in clinical practice.

\section{Prevention of NSAID-related ulcers in high-risk patients}

As mentioned earlier, in patients at high gastrointestinal risk, the rate of recurrent endoscopic or complicated ulcers is still high, despite using COX-2 or traditional NSAIDs plus a proton pump inhibitor for secondary prevention. Combining a selective COX-2 inhibitor with a proton pump inhibitor may confer added protection against gastrointestinal toxicity.

Scheiman et $\mathrm{al}^{54}$ assessed esomeprazole $20 \mathrm{mg} /$ day or $40 \mathrm{mg} /$ day for ulcer prevention in at-risk patients ( $\geq 60$ years 
and/or ulcer history) taking NSAIDs, including COX-2 inhibitors, in two 6-month multicenter studies (Verification of Esomeprazole for NSAID Ulcers and Symptoms [VENUS] and Prevention of Latent Ulceration Treatment Options [PLUTO]). Patients were allowed to take low-dose aspirin for cardiovascular prevention. An upper endoscopy at baseline and after 1, 3, and 6 months of treatment or at premature withdrawal was performed. Significantly more patients remained ulcer-free with esomeprazole $20 \mathrm{mg}$ and $40 \mathrm{mg}$ than with placebo. These significant reductions were observed for users of both nonselective NSAIDs and COX-2 inhibitors. Among patients who received COX-2 inhibitors, reduction values were $16.5 \%$ for placebo, $0.9 \%$ for esomeprazole $20 \mathrm{mg}$, and $4.1 \%$ for esomeprazole $40 \mathrm{mg}(P<0.001$ and $P=0.002$ versus placebo, respectively). For patients who received nonselective NSAIDs and placebo, 17.1\% developed ulcers compared with $6.8 \%$ of those who received esomeprazole $20 \mathrm{mg}(P<0.001$ versus placebo) and $4.8 \%$ $(P<0.001$ versus placebo) of those who received esomeprazole $40 \mathrm{mg}$. The proportion of patients developing ulcers was similar in each subgroup and they could not establish whether, in patients taking a proton pump inhibitor, the use of a COX-2 inhibitor produces a lower risk of ulcer development than the use of a nonselective NSAID. They conclude that esomeprazole $20 \mathrm{mg}$ is an effective dose for ulcer prevention in users of long-term NSAIDs, traditional NSAIDs, or COX-2 inhibitors.

A randomized controlled trial ${ }^{55}$ compared celecoxib $200 \mathrm{mg}$ twice daily plus esomeprazole $20 \mathrm{mg}$ twice daily $(\mathrm{n}=137)$ and celecoxib $200 \mathrm{mg}$ twice daily plus placebo $(\mathrm{n}=136)$ in patients negative for $H$. pylori who had been hospitalized for upper gastrointestinal bleeding associated with nonselective NSAID use. The primary endpoint was recurrent ulcer bleeding during treatment or within 1 month of the end of treatment. After 13 months, the primary endpoint was $0 \%$ in the combined treatment group and $8.9 \%$ in the controls (95\% CI 4.1\%-13.7\%; $P=0.0004)$.

A population-based study compared 1382 patients with upper gastrointestinal complications who were taking a conventional NSAID or a COX-2 inhibitor with 33,957 controls matched for age and gender. ${ }^{56}$ Cotherapy with a proton pump inhibitor, misoprostol, or a COX-2 inhibitor significantly reduced the risk of upper gastrointestinal complications. COX-2 inhibitors were not more likely to prevent complications compared with proton pump inhibitors, but were superior to low-dose misoprostol. The combination of a COX-2 inhibitor with a proton pump inhibitor was associated with the greatest reduction in risk (adjusted OR 0.36, 95\% CI
$0.28-0.47)$ versus an OR of 0.67 (95\% CI $0.48-0.95)$ for a proton pump inhibitor plus a conventional NSAID.

\section{Cost-effectiveness: COX-2 versus combination therapy}

Brown et $\mathrm{al}^{57}$ published a systematic review in 2006 with economic modeling comparing five strategies for preventing NSAID-related gastrointestinal toxicity. They found no direct comparisons between active gastroprotective strategies, so they used indirect comparisons to help understand the relative efficacy of these strategies. Economic modeling suggests that a COX-1 NSAID plus an $\mathrm{H}_{2}$ RA or a COX-1 NSAID plus a proton pump inhibitor are the most cost-effective strategies for avoiding endoscopic ulcers in patients requiring longterm NSAID therapy. Misoprostol is more effective, but is associated with a greater cost and gastrointestinal side effects, which may be unacceptable to patients. However, when assessing serious gastrointestinal events, the economic analysis is sufficiently weakened by the data available as to render clear practice recommendations impossible. Finally, they concluded that more randomized controlled trials directly comparing prevention strategies were needed to arrive at a conclusion.

Latimer et $\mathrm{al}^{58}$ performed a cost-effectiveness analysis in the UK of COX-2 selective inhibitors and traditional NSAIDs alone or in combination with a proton pump inhibitor for patients with osteoarthritis. The main outcome measure was cost-effectiveness of 3 months of treatment, which was based on quality-adjusted life years gained. The analysis was based on data taken from three large randomized controlled trials with COX-2 inhibitors, ie, the Multinational Etoricoxib and Diclofenac Arthritis Long-term Program (MEDAL) ${ }^{59}$ comparing etoricoxib and diclofenac, the CLASS study ${ }^{20}$ with celecoxib, diclofenac, and ibuprofen, and the Therapeutic Arthritis Research and Gastrointestinal Event Trial (TARGET) $^{60,61}$ with lumiracoxib, ibuprofen, and naproxen. Quality-adjusted life year scores were calculated from pooled estimates of efficacy and major adverse events (including gastrointestinal side effects like dyspepsia, symptomatic ulcer, complicated gastrointestinal perforation, ulcer or bleed, and also cardiovascular events like myocardial infarction, stroke, and heart failure). The cheapest proton pump inhibitor was used for analysis (currently omeprazole in the UK). An intervention is classed as cost-effective in UK if the incremental cost of an additional quality-adjusted life year is less than $£ 20,000$. The addition of a proton pump inhibitor to any COX-2 or to other NSAIDs increases the estimated gain in quality-adjusted life years at little additional cost, 
when taking into account the costs avoided from a decreased incidence of NSAID-related gastrointestinal adverse events and the fact that many of these drugs are available as low-cost generics. Coprescription of a proton pump inhibitor costs less than $£ 1000$ per additional quality-adjusted life year gained, even for patients at low risk of gastrointestinal adverse events. Unlike previous analyses, they concluded that the addition of a proton pump inhibitor to both traditional NSAIDs and COX-2 selective inhibitors was likely to be cost-effective on the basis of the latest data and prices.

According to this analysis, in the UK, for people with osteoarthritis and lower risk of cardiovascular adverse events, a COX-2 selective inhibitor plus a proton pump inhibitor might be the most cost-effective treatment option. For patients at increased risk for cardiovascular or gastrointestinal events, paracetamol results in fewer adverse events and is more cost-effective than any traditional NSAID coprescribed with a proton pump inhibitor, but is not superior to a COX-2 selective inhibitor with a proton pump inhibitor. However, we have to take into account that most people with osteoarthritis are elderly and have multiple comorbidities, especially cardiovascular disease, which will limit the use of both COX-2 selective inhibitors and traditional NSAIDs.

\section{Conclusion}

NSAIDs and COX-2 selective inhibitors are useful pharmacological treatment options for symptom relief in patients with osteoarthritis and rheumatoid arthritis. They appear to be equally effective. Both COX-2 selective inhibitors and traditional NSAIDs have high rates of side effects, and there are many questions about their long-term efficacy and safety. When they are prescribed to control symptoms of osteoarthritis and rheumatoid arthritis, they should be used at the lowest effective dose for the shortest possible period of time.

Assessment of individual patient risk (cardiovascular, renal, gastrointestinal) is necessary before prescribing antiinflammatory treatments. To minimize the NSAID-related risk, clinicians should choose a gastroprotective strategy. This may include coprescribing a proton pump inhibitor with a traditional NSAID, using a COX-2 selective inhibitor with or without a proton pump inhibitor. COX-2 inhibitors have been demonstrated to reduce the risk of both upper and lower gastrointestinal events, while proton pump inhibitors would not be expected to protect against the latter. Some cost-effectiveness data have shown that combination of a COX-2 inhibitor and a proton pump inhibitor may be cost-effective in the UK, even in low-risk patients. This issue needs to be examined further in other countries for confirmation. In the past, it has been considered unusual to coprescribe a proton pump inhibitor with a COX-2 selective inhibitor. Thus, this recommendation represents a change in current practice.

\section{Acknowledgments}

The authors gratefully acknowledge the advice of Catoggio LJ, MD, and Soriano ER, MD, Sección Reumatología, Servicio de Clínica Médica, Hospital Italiano de Buenos Aires.

\section{Disclosure}

The authors report no conflicts of interest in this work.

\section{References}

1. Hochberg MC, Lawrence RC, Everett DF, Cornoni-Huntley J. Epidemiologic associations of pain in osteoarthritis of the knee: data from the National Health and Nutrition Examination Survey and the National Health and Nutrition Examination-I Epidemiologic Follow-up Survey. Semin Arthritis Rheum. 1989;18(4 Suppl 2):4-9.

2. Towheed TE, Maxwell L, Judd MG, Catton M, Hochberg MC, Wells G. Acetaminophen for osteoarthritis. Cochrane Database Syst Rev. 2006; 1:CD004257.

3. Hochberg MC, Silman AL, Smolen JS, Weinblatt ME, Weisman MH. Rheumatology. 4th ed. Edinburgh, UK: Mosby Elsevier; 2007.

4. Moore RA, Derry S, McQuay HJ. Cyclo-oxygenase-2 selective inhibitors and nonsteroidal antiinflammatory drugs: balancing gastrointestinal and cardiovascular risk. BMC Musculoskelet Disord. 2007;8:73.

5. Breder CD, Dewitt D, Kraig RP. Characterization of inducible cyclooxygenase in rat brain. J Comp Neurol. 1995;355:296-315.

6. Topper JN, Cai J, Falb D, Gimbrone MA. Identification of vascular endothelial genes differentially responsive to fluid mechanical stimuli: Cyclooxygenase-2, manganese superoxide dismutase, and endothelial cell nitric oxide synthase are selectively up-regulated by steady laminar shear stress. Proc Natl Acad Sci U S A. 1996;93:10417-10422.

7. FitzGerald GA, Patrono C. The coxibs, selective inhibitors of cyclooxygenase-2. N Engl J Med. 2001;345:433-442.

8. Roberts LJ, Morrow JD. Analgesic-antipyretic and antiinflammatory agents and drugs employed in the treatment of gout. In: Hardman JG, Limbird LE, editors. Goodman and Gilman's The Pharmacological Basis of Therapeutics. 10th ed. McGraw-Hill Companies; 2001.

9. Simon LS, Weaver AL, Graham DY, et al. Antiinflammatory and upper gastrointestinal effects of celecoxib in rheumatoid arthritis: a randomized controlled trial. JAMA. 1999;282:1921-1928.

10. Zhao SZ, Fiechtner JI, Tindall EA, et al. Evaluation of health-related quality of life of rheumatoid arthritis patients treated with celecoxib. Arthritis Care Res. 2000;13:112-121.

11. Garner S, Fidan D, Frankish R, et al. Celecoxib for rheumatoid arthritis. Cochrane Database Syst Rev. 2002;4:CD003831.

12. Bensen WG, Fiechtner JJ, McMillen JI, et al. Treatment of osteoarthritis with celecoxib, a cyclooxygenase- 2 inhibitor: a randomized controlled trial. Mayo Clin Proc. 1999;74:1095-1105.

13. Kivitz AJ, Moskowitz RW, Woods E, et al. Comparative efficacy and safety of celecoxib and naproxen in the treatment of osteoarthritis of the hip. J Int Med Res. 2001;29:467-479.

14. Goldstein JL, Correa P, Zhao WW, et al. Reduced incidence of gastroduodenal ulcers with celecoxib, a novel cyclooxygenase-2 inhibitor, compared to naproxen in patients with arthritis. Am J Gastroenterol. 2001;96:1019-1027.

15. Emery P, Zeidler H, Kvien TK, et al. Celecoxib versus diclofenac in long-term management of rheumatoid arthritis: randomised doubleblind comparison. Lancet. 1999;354:2106-2111. 
16. McKenna F, Borenstein D, Wendt H, Wallemark C, Lefkowith JB, Geis GS. Celecoxib versus diclofenac in the management of osteoarthritis of the knee. Scand J Rheumatol. 2001;30:11-18.

17. Singh G, Fort JG, Goldstein JL, et al; for the SUCCESS-I investigators celecoxib versus naproxen and diclofenac in osteoarthritis patients: SUCCESS-I study. Am J Med. 2006;119:255-266.

18. Larkai EN, Smith JL, Lidsky MD, et al. Gastroduodenal mucosa and dyspeptic symptoms in arthritic patients during chronic nonsteroidal antiinflammatory drug use. Am J Gastroenterol. 1987;82: 1153-1158.

19. Laine L. Nonsteroidal anti-inflammatory drug gastropathy. Gastrointest Endosc Clin North Am. 1996;6:489-504 .

20. Silverstein FE, Faich G, Goldstein JL, et al. Gastrointestinal toxicity with celecoxib vs nonsteroidal anti-inflammatory drugs for osteoarthritis and rheumatoid arthritis: the CLASS study: a randomized controlled trial. Celecoxib Long-term Arthritis Safety Study. JAMA. 2000; 284:1247-1255.

21. Bombardier C, Laine L, Reicin A, et al. Comparison of upper gastrointestinal toxicity of rofecoxib and naproxen in patients with rheumatoid arthritis. VIGOR study group. $N$ Engl J Med. 2000;343: 1520-1528.

22. Singh G. Gastrointestinal complications of prescription and over-the-counter nonsteroidal anti-inflammatory drugs: a view from the ARAMIS database. Arthritis, Rheumatism, and Aging Medical Information System. Am J Ther. 2000;7:115-121.

23. Singh G, Triadafilopoulos G. Epidemiology of NSAID induced gastrointestinal complications. J Rheumatol Suppl. 1999;56:18-24.

24. Wolfe MM, Lichtenstein DR, Singh G. Gastrointestinal toxicity of nonsteroidal anti-inflammatory drugs. $N$ Engl J Med. 1999;340: 1888-1899.

25. Gabriel SE, Jaakkimainen L, Bombardier C. Risk for serious gastrointestinal complications related to use of nonsteroidal antiinflammatory drugs. A meta-analysis. Ann Intern Med. 1991;115 787-796 .

26. Bellary SV, Isaacs PE, Lee FI. Upper gastrointestinal lesions in elderly patients presenting for endoscopy; relevance of NSAID usage. Am J Gastroenterol. 1991;86:961-964.

27. Fries JF, Williams CA, Bloch DA, et al. Nonsteroidal anti-inflamatory drug-associated gastropathy: incidence and risk factor models. $\mathrm{Am}$ J Med. 1991;91:213-222.

28. Lanza FL, Chan FK, Quigley EM. Practice Parameters Committee of the American College of Gastroenterology. Guidelines for prevention of NSAID-related ulcer complications. Am J Gastroenterol. 2009; 104:728-738.

29. Zimmermann KC, Sarbia M, Schror K, Weber AA. Constitutive cyclooxygenase-2 expression in healthy human and rabbit gastric mucosa. Mol Pharmacol. 1998;54:536-540.

30. Huang JQ, Sridhar S, Hunt RH. Role of Helicobacter pylori infection and nonsteroidal anti-inflammatory drugs in peptic-ulcer disease: a meta-analysis. Lancet. 2002;359:14-22.

31. Vergara M, Catalan M, Gisbert JP, et al. Meta-analysis: role of Helicobacter pylori eradication in the prevention of peptic ulcer in NSAID users. Aliment Pharmacol Ther. 2005;21:1411-1418.

32. Leontiadis GI, Sreedharan A, Dorward S, et al. Systematic reviews of the clinical effectiveness and cost-effectiveness of proton pump inhibitors in acute upper gastrointestinal bleeding. Health Technol Assess. 2007; 11:1-164.

33. Rostom A, Dube C, Wells G, et al. Prevention of NSAID-induced gastroduodenal ulcers. Cochrane Database Syst Rev. 2002;4: CD002296. DOI: 10.1002/14651858.CD002296.

34. Bardhan KD, Ahlberg J, Hislop WS, et al. Rapid healing of gastric ulcers with lansoprazole. Aliment Pharmacol Ther. 1994;8:215-220.

35. Agrawal NM, Campbell DR, Safdi MA, et al. Superiority of lansoprazole vs ranitidine in healing nonsteroidal anti-inflammatory drug-associated gastric ulcers: results of a double-blind, randomized, multicenter study - NSAID-Associated Gastric Ulcer Study Group. Arch Intern Med. 2000;160:1455-1461.
36. Yeomans ND, Tulassay Z, Juhasz L, et al. A comparison of omeprazole with ranitidine for ulcers associated with nonsteroidal antiinflammatory drugs: acid Suppression Trial: ranitidine versus Omeprazole for NSAID-associated Ulcer Treatment (ASTRONAUT) Study Group. N Engl J Med. 1998;338:719-726.

37. Goldstein JL, Johanson JF, Hawkey CJ, et al. Clinical trial: healing of NSAID-associated gastric ulcers in patients continuing NSAID therapy: a randomized study comparing ranitidine with esomeprazole. Aliment Pharmacol Ther. 2007;26:1101-1111.

38. Goldstein JL, Johanson JF, Suchower LJ, et al. Healing of gastric ulcers with esomeprazole versus ranitidine in patients who continued to receive NSAID therapy: a randomized trial. Am J Gastroenterol. 2005;100:2650-2657.

39. Arora G, Singh G, Triadafilopoulos G. Proton pump inhibitors for gastroduodenal damage related to nonsteroidal anti-inflammatory drugs or aspirin: twelve important questions for clinical practice. Clin Gastroenterol Hepatol. 2009;7:725-735.

40. Yeomans ND, Svedberg LE, Naesdal J. Is ranitidine therapy sufficient for healing peptic ulcers associated with non-steroidal anti-inflammatory drug use? Int J Clin Pract. 2006;60:1401-1407.

41. Weinblatt ME, Genovese MC, Kivitz AJ, et al. Efficacy, safety and tolerability of HZT-501, including users of low-dose aspirin, a single-tablet combination of ibuprofen-famotidine: results of two Phase 3 trials. Arthritis Rheum. 2010;62(Suppl 10):945 DOI: 10.1002/art.28713

42. Silverstein FE, Graham DY, Senior JR, et al. Misoprostol reduces serious gastrointestinal complications in patients with rheumatoid arthritis receiving nonsteroidal anti-inflammatory drugs. A randomized, doubleblind, placebo-controlled trial. Ann Intern Med. 1995;123:241-249.

43. Raskin JB, White RH, Jackson JE, et al. Misoprostol dosage in the prevention of nonsteroidal anti-inflammatory drug-induced gastric and duodenal ulcers: a comparison of three regimens. Ann Intern Med. 1995; 123:344-350.

44. Koch M, Dezi A, Ferrario F, Capurso I. Prevention of nonsteroidal anti-inflammatory drug-induced gastrointestinal mucosal injury. A meta-analysis of randomized controlled clinical trials. Arch Intern Med. 1996;156:2321-2332.

45. Graham DY, Agrawal NM, Campbell DR, et al. Ulcer prevention in long-term users of nonsteroidal anti-inflammatory drugs: results of a double-blind, randomized, multicenter, active. and placebo-controlled study of misoprostol vs lansoprazole. Arch Intern Med. 2002;162: $160-175$.

46. Hooper L, Brown TJ, Elliott R, Payne K, Roberts C, Symmons D. The effectiveness of five strategies for the prevention of gastrointestinal toxicity induced by non-steroidal anti-inflammatory drugs: systematic review. BMJ. 2004;329:948

47. Okie S. Missing data on Celebrex. Full study altered picture of drug. Washington Post. 2001;5:A11.

48. Wright JM, Perry TL, Bassett KL, Chambers GK. Reporting of 6-month vs 12-month data in a clinical trial of celecoxib. JAMA. 2001;286: 2398-2400.

49. Hrachovec JB, Mora M. Reporting of 6-month vs 12-month data in a clinical trial of celecoxib. JAMA. 2001;286:2398.

50. Jüni P, Rutjes AW, Dieppe PA. Are selective COX 2 inhibitors superior to traditional non steroidal anti-inflammatory drugs? BMJ. 2002;324: 1287-1288.

51. Chan FK, Hung LC, Suen BY, et al. Celecoxib versus diclofenac and omeprazole in reducing the risk of recurrent ulcer bleeding in patients with arthritis. N Engl J Med. 2002;347:2104-2110.

52. Lai KC, Chu KM, Hui WM, et al. Celecoxib compared with lansoprazole and naproxen to prevent gastrointestinal ulcer complications. Am J Med. 2005; 118:1271-1278

53. Chan FK, Lanas A, Scheiman J, Berger MF, Nguyen H, Goldstein JL. Celecoxib versus omeprazole and diclofenac in patients with osteoarthritis and rheumatoid arthritis (CONDOR): a randomised trial. Lancet. 2010;376:173-179.

54. Scheiman JM, Yeomans ND, Talley NJ, et al. Prevention of ulcers by esomeprazole in at-risk patients using non-selective NSAIDs and COX-2 inhibitors. Am J Gastroenterol. 2006;101:701-710. 
55. Chan FK, Wong VW, Suen BY, et al. Combination of a cyclooxygenase-2 inhibitor and a proton-pump inhibitor for prevention of recurrent ulcer bleeding in patients at very high risk: a double-blind, randomised trial. Lancet. 2007;369:1621-1626.

56. Targownik LE, Metge CJ, Leung S, Chateau DG. The relative efficacies of gastroprotective strategies in chronic users of nonsteroidal anti-inflammatory drugs. Gastroenterology. 2008;134:937-944.

57. Brown TJ, Hooper L, Elliott RA, et al. A comparison of the cost-effectiveness of five strategies for the prevention of non-steroidal anti-inflammatory drug-induced gastrointestinal toxicity: a systematic review with economic modeling. Health Technol Assess. 2006;10: $1-183$.

58. Latimer N, Lord J, Grant RL, O’Mahony R, Dickson J, Conaghan PG; National Institute for Health and Clinical Excellence Osteoarthritis Guideline Development Group. Cost effectiveness of COX 2 selective inhibitors and traditional NSAIDs alone or in combination with a proton pump inhibitor for people with osteoarthritis. BMJ. 2009;339:b2538.
59. Laine L, Curtis SP, Cryer B, Kaur A, Cannon C. Assessment of upper gastrointestinal safety of etoricoxib and diclofenac in patients with osteoarthritis and rheumatoid arthritis in the Multinational Etoricoxib and Diclofenac Arthritis Long-term (MEDAL) programme: a randomised comparison. Lancet. 2007;369:465-473.

60. Farkouh ME, Kirschner H. Comparison of lumiracoxib with naproxen and ibuprofen in the Therapeutic Arthritis Research and Gastrointestinal Event Trial (TARGET), cardiovascular outcomes: randomised controlled trial. Lancet. 2004;364:675-684.

61. Schnitzer TJ, Burmester GR, Mysler E. Comparison of lumiracoxib with naproxen and ibuprofen in the Therapeutic Arthritis Research and Gastrointestinal Event Trial (TARGET), reduction in ulcer complications: randomised controlled trial. Lancet. 2004;364:665-674.

\section{Publish your work in this journal}

Open Access Rheumatology Research and Reviews is an international, peer-reviewed, open access journal, publishing all aspects of clinical and experimental rheumatology in the clinic and laboratory including the following topics: Pathology, pathophysiology of rheumatological diseases; Investigation, treatment and management of rheumatological diseases; Clinical trials and novel pharmacological approaches for the treatment of rheumatological disorders. The manuscript management system is completely online and includes a very quick and fair peerreview system, which is all easy to use. Visit http://www.dovepress.com/ testimonials.php to read real quotes from published authors. 